\title{
Visual form perception: Task demands and congruence among spatial solutions'
}

LEONA S. AIKEN and D. R. BROWN, Purdue University, Lafayette, Ind. 47907

Multidimensional scaling techniques were used to examine the nature of pattern discrimination in the presence of visual noise. These results were compared to a spatial analysis of similarity judgments and of discrimination latencies. The latter two spaces were highly congruent in three dimensions. The noise data were similar to a previous spatial analysis of discriminationin-noise, but not congruent with the similarity and latency spaces.

In previous studies, nonmetric multidimensional scaling (MDS) analyses were used to study pattern discrimination in noise (Aiken \& Brown, in press, a) and to compare discrimination results to spatial analyses of similarity and discrimination difficulty judgments (Aiken \& Brown, in press, b). All three tasks yielded interpretable results in three dimensions when the Euclidian metric was used for similarity judgments and $r=3.0$ was used as the metric for the discrimination difficulty judgments and for the discrimination of patterns in noise. When the three spaces were compared through canonical correlation techniques, a higher degree of congruence was found between the two judgment spaces than between either judgment space and the discrimination-in-noise space.

The present study was carried out to provide similar data for a new sample of patterns. In previous studies, apparently similar MDS results were obtained for similarity judgments (Behrman \& Brown, 1968) and for discrimination latencies (Brown \& Andrews, 1968). In this study, discrimination-in-noise data were collected and analyzed using MDS procedures, and the three spaces were compared using canonical correlation analy ses.

\section{PATTERNS}

The sample of 16 four-sided random polygons illustrated in previous studies (Behrman \& Brown, 1968; Brown \& Andrews, 1968) was used. A complete description of the method of construction and quantification used has been described elsewhere (Brown \& Owen, 1967), and the
A 3-by-3 Latin square control design was used with days assigned to columns, three groups of four students each assigned to sequences (rows), and three blocks of 40 problems each assigned to cells. Within each block, problems were randomly sequenced. Each group was further divided in to two groups for whom a different pattern served as the correct stimulus in each pair. Fifteen randomly chosen problems were repeated to provide reliability data.

\section{RESULTS}

method by which the discrimination problems were constructed in noise has been described in detail previously (Aiken \& Brown, in press, a). To mask the stimuli, noise matrices, consisting of from $98 \%$ to $60 \%$ noise, were superimposed upon the forms. The noise matrices were constructed by sampling cells of a 100-by-100 matrix randomly, without replacement, at $2 \%$ increments. The results are illustrated for selected noise levels in Fig. 1.

\section{PROCEDURE}

Discrimination problems involved presenting the $\left(\begin{array}{c}16 \\ 2\end{array}\right)$ pairs of patterns. On each problem, the particular pair of patterns was back-projected on a screen with one of the pair presented in $98 \%$ noise immediately to the left of the pair. This latter slide was followed at 1.5 -sec intervals by slides of progressively decreasing noise which continued until the $S$ responded "right" or "left" to identify which member of the pair was imbedded in noise. The response deactivated the projectors through a voice key and the dependent variable was the per cent of noise present at the point of accurate discrimination. Ss were instructed to respond as soon as they could make accurate discriminations, but to avoid errors. While rare, when an error occurred, the problem was repeated at a later random position in the sequence.

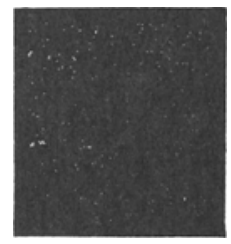

$98 \%$

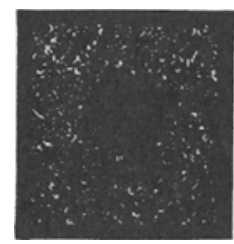

$92 \%$

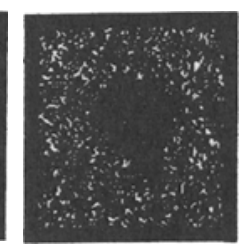

$86 \%$

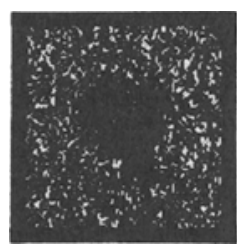

$80 \%$

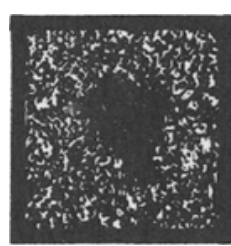

$74 \%$

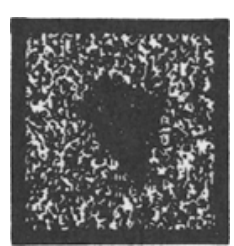

$68 \%$

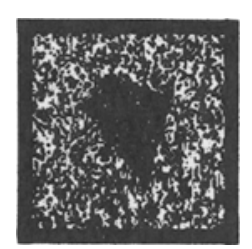

$62 \%$
Fig. 1. Illustration of a pattern imbedded in visual noise at selected levels. 
Table 1

Intercorrelations Among Physical Pattern Measures and Dimensions of the $\mathrm{r}=3.0$, Two- and ThreeDimensional Solutions (Sign and Decimals Omitted)

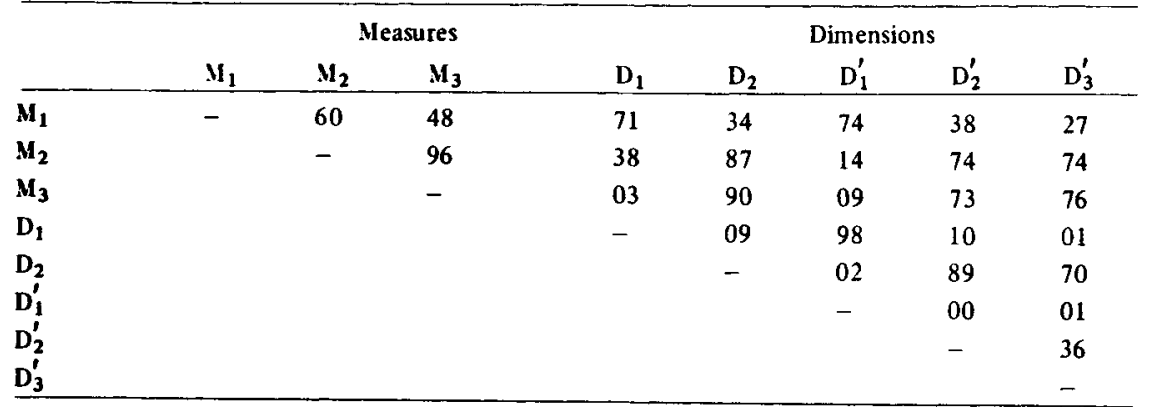

$\begin{aligned} M_{1}: & \text { Variance of interior angle sizes in degrees. } \\ M_{2}: & \text { Horizontal extent (maximum width) of the pattern. } \\ M_{3}: & \text { Variance of the area units collapsed to the } \chi \text { axis. } \\ D_{1}-D_{2}: & \text { Dimensions of the } r=3, \text { two-dimensional solution. } \\ D_{1}^{\prime}-D_{3}^{\prime}: & \text { Dimensions of the } r=3, \text { three-dimensional solution. }\end{aligned}$

among dimensions, and between measures and dimensions. The two-dimensional solution has a compelling interpretation. The first dimension correlated most highly with variability of angle sizes (.74) and was labelled "jaggedness." The second dimension, correlated with the variance of area units along the $\chi$ axis (.90), is interpreted as an indicant of "horizontal dispersion." It is interesting to note that very similar dimensions were obtained in the previous study of discrimination in noise using eight-sided polygons (Aiken \& Brown, in press, a).

The three-dimensional solution, though closely related to the physical measuring system, poses a problem in interpretation. Though the first two dimensions of this space essentially reproduce the twodimensional space, i.e., $\mathrm{I}_{\mathrm{D}_{1}} \mathrm{D}^{\prime}{ }_{1}=.98$, and $I_{D_{2}} D_{2}^{\prime}=.89$, the third dimension is not uniquely interpretable. All measures with which Dimension 3 is highly correlated $(r>.70)$ are also correlated to the same degree with Dimension 2. Thus, it is concluded that the two-dimensional configuration is a sufficient solution space.

In order to compare these results with previous spatial analyses of discrimination

Table 2

Canonical Correlations Comparing the Similarity Space $\left(S_{1}\right)$, Discrimination Latency Space $\left(S_{2}\right)$, and Discrimination-in-Noise Space in Two $\left(S_{3}\right)$ and Three $\left(S_{4}\right)$ Dimensions

\begin{tabular}{lllll}
\hline \multicolumn{5}{c}{ Canonical Correlations $\begin{array}{l}\text { Total } \\
\text { Common } \\
\text { Variance }\end{array}$} \\
\hline $\mathrm{S}_{1}-\mathrm{S}_{2}$ & $.97^{* *}$ & $.92^{* *}$ & $.85^{* *}$ & .83 \\
$\mathrm{~S}_{1}-\mathrm{S}_{3}$ & $.83^{* *}$ & .41 & - & .28 \\
$\mathrm{~S}_{1}-\mathrm{S}_{4}$ & .83 & .31 & .14 & .27 \\
$\mathrm{~S}_{2}-\mathrm{S}_{3}$ & $.77^{*}$ & .39 & - & .25 \\
$\mathrm{~S}_{2}-\mathrm{S}_{4}$ & .77 & .35 & .27 & .26 \\
\hline
\end{tabular}

$* * p \leqslant .01$

$* P<.05$ latency (Brown \& Andrews, 1968) and similarity judgments (Behrman \& Brown, 1968) canonical correlation analyses were used. A more complete treatment of this topic may be found in several recent studies (Aiken \& Brown, in press, b; Stenson, 1968).

The results of these analyses are shown in Table 2. The squared canonical correlations may be interpreted as the maximum proportion of variance shared by linear combinations (canonical variates) from the two solutions. The last column gives the total per cent of common variance shared by the two sets of variates. It is clear that the similarity and discrimination latency spaces were remarkably congruent. For instance, the first canonical variates, which weighted a "compactness" dimension from each solu. second variates, weighting the "jaggedness" dimensions, shared $83 \%$ variance; and the third variates, which combined all three discrimination dimensions, shared $71 \%$ variance with the "compactness" dimension of the similarity space. The two spaces shared $83 \%$ common variance. Only one major point need be noted concerning all comparisons of the two- and threedimensional discrimination-in-noise spaces with the other two configurations. First, only one canonical variate related any of the solutions based on the criterion of a significant canonical correlation. In each case what was labelled the "jaggedness" dimension for the noise data was most congruent with the "compactuess" dimension of both the latency and similarity space. All other comparisons may be considered as error. That "jaggedness" and "compactness" should be related is not strange in view of the fact that angle characteristics largely determine dispersion with four-sided patterns. tion, shared $94 \%$ common variance; the

\section{DISCUSSION}

Several aspects of these results should be emphasized. First, the high degree of congruence between configurations based on similarity estimates and discrimination latencies suggests, as previously noted (Brown \& Andrews, 1967), that a common set of pattern features underlies performance in superficially different tasks. It is also worth noting that similar configurations have previously been obtained when two judgment tasks were compared (Aiken \& Brown, in press, b). When discrimination occurs in the presence of visual noise, however, a somewhat different set of dimensions arises, and these differences seem to be stable across studies. Previously, with eight-sided polygons we obtained a solution in which two dimensions were highly similar to those obtained in the present analysis. The solutions, unfortunately, cannot be compared statistically since different patterns were used. Moreover, in both studies the best solution involved a metric higher than the more commonly used city block $(r=1.0)$ or Euclidean $(r=2.0)$ metrics. While these data are not definitive with regard to the complex question of selecting a metric, it does seem intuitively appealing that Os would give more weight to larger differences among patterns in the presence of noise which would result in better fit with a higher-order metric.

Overall, these studies suggest that task demands in part determine the specific features of patterns which will be abstracted and may determine the appropriate spatial model for how Os combine aspects of stimulation into a unitary response.

\section{REFERENCES}

AIKEN, L. S., \& BROWN, D. R. A spatial analysis of the discriminability of forms in noise. Perception \& Psychophysics, in press, a.

AIKEN, L. S., \& BROWN, D. R. Visual form perception: Congruence among spatial configurations. Perception \& Psychophysics, in press, $b$.

BEHRMAN, B. W., \& BROWN, D. R. Multidimensional scaling of form: A psychophysical analysis. Peraption \& Psychophysics, 1968,4, 19.25.

BROWN, D. R., \& ANDREWS, M. H. Visual form discrimination: Multidimensional analy ses. Perception \& Psychophysics, 1968, 3, 401-406.

BROWN, D. R., \& OWEN, D, H. The metrics of visual form: Methodological dy spepsia. Psy cho logical Bulle tin, 1967, 68, 243-259.

KRUSKAL, J. B. Multidimensional scaling by optimizing goodness of fit to a nonmetric hypothesis. Psychometrika, 1964a, 29, 1-27.

KRUSKAL, J. B. Multidimensional scaling: A numerical method. Psychometrika, 196+b, 29, 115.119.

STENSON, H. H. The psy chophysical dimensions of similarity among random shapes. Perception \& Pyychophysics, 1968, 3, 201-214. NOTE

1. This research was supported by Research Grant HD 00909 from the National Institute of Child Health and Human Development. 